\title{
DE CÓMO EL HOMBRE LLEGÓ A SER PERSONA: LOS ORÍGENES DE UN CONCEPTO JURÍDICO-FILOSÓFICO EN EL DERECHO ROMANO
}

[On how Man became Person: the Origins of a Legal-Philosophical Concept in Roman Law]

\author{
Jakob ForTUNAT STAGL* \\ Universidad Bernardo O'Higgins, Santiago, Chile \\ Rheinische Friedrich Wilhelms-Universität, Bonn, Alemania
}

\begin{abstract}
RESUMEN
Hasta el momento en que nació Cristo, De iure personarum era un dispositivo del derecho romano para la descripción y la ejecución de la precedencia del pater familias sobre el resto de la sociedad romana: esclavos, libertos, extranjeros, cónyuges e hijos. La traducción correcta sería, por tanto, "Derecho de los estatus sociales". Gracias a la influencia del derecho natural, la idea de libertad e igualdad ganó terreno que está basada en un concepto unitario de hombre. Para expresar esta idea los juristas romanos recurrieron al término persona en lugar de homo porque este último era una
\end{abstract}

\begin{abstract}
Until the birth of Christ, De iure personarum was a construct in Roman law used to describe and execute the precedence of the pater familias over the rest of the Roman society: slaves, freed slaves, foreigners, spouses and children. Then, the right translation is "Law of the social status". Due to the influence of natural law, the idea of freedom and equality, based on a unitary concept of the man, gained ground. In order to express this idea, the Roman lawyers used the term persona instead of homo since the latter is a technical expression referring to a slave and the former already
\end{abstract}

RECIBIDO el 14 de julio y ACEPTADO el 7 de diciembre de 2015

* Profesor de la Universidad Bernardo O’Higgins, Santiago, Chile; Docente de la Rheinische Friedrich Wilhelms-Universität, Bonn, Alemania. Dirección postal: General Gana 1702, Santiago Centro, Chile. Correo electrónico: jakob.stagl@yahoo.de 
expresión técnica para mentar al esclavo y el primero ya tenía una amplia variedad de significados. Persona que, hasta ahora ha descrito cadenas del hombre, ahora se convirtió en un término para sus derechos adquiridos de la igualdad y la libertad. Este es el significado de la palabra latina persona que entró en la teología y la filosofía y llegó a ser uno de los conceptos jurídicos e ideas filosóficas más importantes de Occidente.

Palabras Clave

Persona-Hombre-Derecho natural - Sociedad patriarcal - Humanitas. had several meanings. Persona, a word that until then had been used to describe enchained men, now became a term for their vested rights of equality and freedom. This is the meaning of the Latin word persona that was adopted by the disciplines of theology and philosophy and became one of the most important legal concepts and philosophical ideas of the Western world.

KEYWORDS
Person - Men - Natural Law - Pa-
triarchal Society - Humanitas

KEYWORDS

triarchal Society - Humanitas

\section{LA FUNCIÓN DEL CONCEPTO DE PERSONA EN EL DERECHO}

El concepto de persona ${ }^{1}$ en el derecho moderno tiene tres funciones: abstraer, clasificar y - tal vez la más importante - provocar el pathos. El concepto de persona es una abstracción ${ }^{2}$. Esta abstracción individualiza al ser humano con referencia al sistema jurídico. Así se define de manera adecuada el Preußisches Allgemeines Landrecht de 1794: "El hombre se dice persona en cuanto goza de determinados derechos en la sociedad civil"3. Un sistema jurídico necesita de esta abstracción, es decir, requiere prescindir deliberadamente del particular, en cuanto dispone por sobre todo de reglas generales. De este modo, entonces, no se interesa normalmente por lo singular en cuanto tal, sino más bien otorga diversos derechos a diferentes grupos de individuos. Así, por ejemplo, todos los chilenos son personas, lo que implica que tienen una misma capacidad jurídica, pero lo son en distinta medida. Según el artículo 25 de la Constitución chilena, por ejemplo, se necesita haber cumplido 40 años para ser elegido presidente de la República. Los jóvenes, entonces, tienen la desventaja de no poder ser elegidos presidente. Es posible formular de manera más fácil distinciones de esta naturaleza, que pueden variar mucho en el tiempo y

\footnotetext{
${ }^{1}$ Especialmente sobre el punto PerLINGIERI, Pietro, La personalità umana nel ordinamento giuridico (Napoli, 1972), passim.

${ }^{2}$ Lyon Puelma, Alberto, Personas naturales (Santiago, 2007), p. 18.

${ }^{3}$ I,1 $\$ 1$ Preuß. ALR: "Der Mensch wird, sofern er gewisse Rechte in der bürgerlichen Gesellschaft genießt, Person genannt”. V. también Kelsen, Hans, Allgemeine Staatslehre (Berlin, 1925), p. 63; y Lyon Puelma, Alberto, cit. (n. 2), p. 18.
} 
en el espacio, si no se mira al hombre concreto sino que a la abstracción de la persona. Las abstracciones muestran un aspecto más imparcial que las denominaciones concretas. El término jurídico de persona, en lugar de 'hombre', cumple entonces -sobre la base de un primer razonamiento- la función de servir como punto de conexión lingüística entre las diferencias existentes entre determinados grupos de hombres. Por tanto, el concepto de persona representa, como observa correctamente Rodotà, no solamente la naturaleza del hombre, sino, por sobre todo y siempre, una construcción - con vencedores y vencidos ${ }^{4}$. En esto reside el riesgo, como muestra la historia, de que a través del concepto de persona los hombres hayan sido privados de los derechos de modo intolerable.

En el derecho civil chileno cada ser humano -nacido- es una persona. Dice el artículo 55 CCCh. "Son personas todos los individuos de la especie bumana, cualquiera que sea su edad, sexo, estirpe o condición. Divídense en chilenos y extranjeros". Según el artículo 74 CCCh., el hombre adquiere la capacidad jurídica con el perfeccionamiento de su nacimiento: "La existencia legal de toda persona principia al nacer, esto es, al separarse completamente de su madre. La criatura que muere en el vientre materno, o que perece antes de estar completamente separada de su madre, o que no haya sobrevivido a la separación un momento siquiera, se reputará no haber existido jamás.” Entonces, con el nacimiento, el ordenamiento jurídico civil dota al hombre del predicado de 'persona', y se agrega la capacidad de ser sujeto de derechos y deberes 5 . Por tanto, el ordenamiento entrelaza la capacidad jurídica del particular con el concepto de persona, con la finalidad de asociar entre sí a las personas en cuanto agrupadas por el hecho de ser sujetos de derechos y deberes ${ }^{6}$.

Para dicho objetivo, el ordenamiento jurídico utiliza el concepto de persona jurídica, en oposición al de persona natural. La creación del concepto de persona jurídica es una operación puramente intelectual, de la cual no se tendría necesidad alguna, pero que el hombre emplea en cuanto tiende a concebir un individuo sujeto de derechos y deberes en los

${ }^{4}$ Rodotà, Stefano, Antropologia del "homo dignus", en Civilistica.com. Revista Eletrónica di Direito Civil, 2 (2013), p. 1.

${ }^{5}$ CoIng, Helmut, Der Rechtsbegriff der menschlichen Person und die Theorien der Menschenrechte, en WolfF, Ernst (editor), Beiträge zur Rechtsforschung. Sonderveröffentlichung der Zeitschrift für Ausländisches und Internationales Privatrecht (Tübingen, 1950), pp. $191 \mathrm{~s}$.

${ }^{6}$ SCHMITT, Jochem: $\$ 1$ sez. 6, en Münchener Kommentar zum BGB (6a edición, München, 2012). 
términos de persona ${ }^{7}$. Las personas naturales y las jurídicas ${ }^{8}$ son los agentes del sistema jurídico ${ }^{9}$, y por eso se dicen sujetos de derecho ${ }^{10}$, mientras que los objetos de derecho son las cosas con las que tales sujetos actúan, o sea, son objetos materiales, como, p. ej., un lápiz, o inmateriales, como las pretensiones y los derechos ${ }^{11}$.

Lo dicho parece totalmente neutral y técnico, pero no es así: con esto llegamos al pathos ${ }^{12}$. Los animales, por ejemplo, no caben en el concepto de persona ${ }^{13}$. Esto era diferente en el antiguo ordenamiento jurídico alemán (de esta manera cuando una vaca, por ejemplo, causaba daño a un hombre era castigada como si fuera una persona humana), y de hecho también en el actual aquel principio ya no está tan patente. Según el texto del artículo 90a del Bürgerliches Gesetzbuch: "los animales no son cosas", y por lo tanto se excluyen de la categoría de los objetos del derecho. Otra problemática es la posición de los seres humanos no nacidos. El llamado nasciturus, en el derecho privado, puede gozar de determinadas ventajas jurídicas bajo la condición de que haya nacido ${ }^{14}$. Así lo afirma el artículo 1923 inciso $2^{\circ}$ BGB.: "Aquel que en el momento de la apertura de la sucesión no se encontraba en vida, pero ya había sido concebido, se considera como nacido antes de la apertura". En cambio, la disposición no se refiere a la cuestión de si el nasciturus tuviera otros derechos ulteriores, como por ej. el de la vida. Sin embargo, el artículo 74 CCCh. manifiesta el contraste con la capacidad jurídica del ser humano no nacido, haciendo depender explícitamente el

${ }^{7}$ Expresión de Windscheid, Bernhard - Kipp, Theodor, Lehrbuch des Pandektenrechts ( $9^{a}$ edición, Frankfurt am Main, 1908), $\$ 49$ n. 2: “die Menschennatur durchziehender tiefer Zug zur Persönlichkeit”. Las teorías sobre la persona jurídica en Lyon Puelma, Alberto, cit. (n. 2), pp. 20-31.

${ }^{8}$ Por consiguiente los derechos fundamentales son aplicables a las personas jurídicas por disposición del artículo 19 inciso 3 de la Constitución alemana. Sobre esto IsENSEe, Josef, Juristische Person, en Isensee, Josef - Kirchhof, Paul (editores), Handbuch des Staatsrecht der Bundesrepublik Deutschland (Heidelberg, 2011), IX

${ }^{9}$ WINDSCHEID, Bernhard - Kipp, Theodor, cit. (n. 7), $\$ 49$ nota 1.

${ }^{10}$ Sobre el término sujeto GUZMÁN BRITO, Alejandro, Derecho privado romano (2a edición, Santiago, 2013), I, pp. 293-294.

${ }^{11}$ Sobre el sujeto de derechos y el objeto de derechos: EnNECCERUs, Ludwig - NipPERDEY, Hans Carl, Allgemeiner Teil des Bürgerlichen Rechts (15a edición, Tübingen, 1959), pp. 444-453.

${ }^{12}$ Para mayores detalles Perlingieri, Pietro, La persona e $i$ suoi diritti (Napoli, 2005), pp. 13-22, passim.

${ }^{13}$ Hattenhauer, Hans, Grundbegriffe des bürgerlichen Rechts (2a edición, München, 2000), $\$ 1$ II.

${ }^{14}$ TAFArO, Sebastiano, "Ius hominum causa constitutum" (Napoli, 2009), pp. 3946. 
inicio de la capacidad jurídica al evento del nacimiento ${ }^{15}$. Esto no significa que no sea posible derivar deductivamente una simple protección a partir de normas jurídica de rango más elevado, como el artículo 19 CPol. Ch.: "La Constitución asegura a todas las personas: $1^{\circ}$. El derecho a la vida y a la integridad física y psíquica de la persona. La ley protege la vida del que está por nacer"16.

En el ordenamiento jurídico chileno no se discute más, a decir verdad, que cada uno -pero también cada ser humano nacido- se inscriba en el artículo 55 CCCh., es decir, que sea "persona" con derechos y deberes (aquello no es natural, como lo era en la Antigüedad, donde existía incluso la obligación moral de matar a los niños discapacitados) $)^{17}$

Ahora bien, el acceso de la persona a los derechos, en cuanto justificado por su naturaleza humana, aquel pathos del concepto de persona, fue formulado por primera vez de la manera más clara en el artículo 16 del Allgemeines Bürgerliches Gesetzbuch de 1811: "Cada hombre tiene derechos innatos, evidentes a través del sentido común, y por lo tanto debe ser considerado como una persona. La esclavitud, la servidumbre de la gleba y el ejercicio de un poder sobre estos, no tiene lugar en estos Estados". Por lo tanto, según esta disposición, cada hombre tiene derechos fundamentales esenciales de libertad e igualdad en cuanto es una persona. Dice artículo 1 CPol.Ch.: "Las personas nacen libres e iguales en dignidad y derechos." En el concepto de persona se cristaliza una ineludible protección mínima del hombre ${ }^{18}$. La tutela de la persona humana es en la actualidad muy importante. ${ }^{19}$ ¿Cómo se ha llegado a que el concepto de persona, en sí mismo neutral, se ha ya enriquecido de pathos iusnaturalista? Para tal propósito es oportuno recurrir a la historia de tal concepto, la cual -nos parece- no ha sido investigada bajo este aspecto.

II. El CONCEPTO ClÁsico ROMANO DE PERSONA: EL HOMBRE EN LAS CADENAS DE LOS "STATUS"

La palabra latina persona indica en un primer momento el revestimiento,

${ }^{15}$ Sobre esto Enneccerus, Ludwig - Nipperdey, Hans Carl, cit. (n. 11), p. 480.

${ }^{16}$ Sobre esto LyOn Puelma, Alberto, cit. (n. 2), pp. 87-98.

${ }^{17}$ Mommsen, Theodor, Römisches Strafrecht (Leipzig, 1899), pp. 618-619.

${ }^{18}$ Maritain, Jacques, Les droits de lhomme et la loi naturelle (Paris, 1947), passim; Giltaij, Jacob, Mensenrechten in het Romeinse recht? (Nijmegen, 2011), pp. 4959, 180-181; así con referencia al derecho italiano vigente Perlingieri, Pietro, La persona e i suoi diritti, cit. (n. 12), pp. 13-14.

${ }^{19}$ Perlingieri, Pietro, La personalità, cit. (n. 1), p. 20. 
o mejor dicho la máscara ${ }^{20}$ de los actores, luego en sentido metafórico el papel que se representa en el escenario y, en seguida, el papel en el mundo ${ }^{21}$. Frente a esto, el término ha adquirido un significado ulterior de 'personalidad'22. En referencia al sistema jurídico, el concepto designa el papel que se desempeña en el proceso, como aquel de juez, actor, imputado o testigo, y más en general, el rol en el sistema jurídico mismo ${ }^{23}$. Ahora bien, hemos sostenido anteriormente la tesis, expresada solamente a nivel teórico, de que el concepto de persona cumple una función deshumanizante por cuanto es abstracto. Esto se detecta en la representación sintética sobre el derecho de las personas ofrecida por Gai. 1,8 ss. y 4824: (8) "Omne ius quo utimur, vel ad personas pertinet vel ad res vel ad actiones. et prius videamus de personis. (9) "Et quidem summa divisio de iure personarum haec est, quod omnes homines aut liberi sunt aut servi". (10) "Rursus liberorum hominum alii ingenui sunt, alii libertini. (48) Sequitur de iure personarum alia diviso. Nam quaedam personae sui iuris sunt, quaedam alieno iuri subiectae sunt" [(8) "Todo el derecho que usamos se refiere o a las personas, o a las cosas, o a las acciones. En primer lugar tratemos de las personas. (9) Ciertamente, la primera división del derecho de personas es ésta: todos los hombres o son libres o son esclavos. (10) A su vez, de los hombres libres, unos son ingenuos; otros, libertos. (48) Sigue otra división del derecho de personas: unas personas son independientes, otras dependen de alguien"].

Si se quisiera dar el significado originario del concepto de persona de la manera más clara posible e independiente de su uso, no se debería traducir la expresión "de iure personarum", como se hace generalmente, como "el derecho de las personas", sino más bien como "el derecho de los estatus sociales". 'Estatus' aquí entendido en el sentido de 'tercer estado', porque

${ }^{20}$ La etimología de la palabra persona en lenguaje latín es muy discutida, BLUMENTHAL, Albrecht von, s.v. "Person", en Kroll, Wilhelm (editor), Realencyclopädie der classischen Altertumswissenschaft, Neue Bearbeitung (Stuttgart, 1937), XXXVI, cols. 1036-1040; sobre esto ahora: Ribas Alba, José María, Persona desde el derecho romano a la teología cristiana (2a edición, Granada, Comares 2012), pp. 105-123, 125-153.

${ }^{21}$ Sobre esto ahora Agnati, Ugo, "Persona iuris vocabulum”. Per un' interpretazione giuridica di persona nelle opere di Gaio, en Rivista di Diritto Romano, 9 (2009), pp. 2-9.

${ }^{22}$ Detalladamente Scarano Ussani, Vincenzo, La scoperta della persona, en Ostraka, 18 (2009), pp. 237-248.

${ }^{23}$ Fuhrmann, Manfred, s. v. "Persona”, en Ritter, Joachim (editor), Historisches Wörterbuch der Philosophie (Darmstadt, 1989), VII, pp. 269-271.

${ }^{24}$ El texto paralelo las Instituciones de Justiano es Inst. 1,3. V. Mantello, Antonio, Lezioni di diritto romano (Torino, 2004), II, pp. 233-246; Quadrato, Renato, "Gaius dixit". La voce di un giurista di frontiera (Bari, 2010), pp. 3-18. 
eso era lo que Gayo y sus Instituciones vislumbraban ${ }^{25}$. Gayo reconduce a todos los seres humanos en el genus de persona con la finalidad de poderlos clasificar en species singulares, y estas especies representan los estatus alrededor de los que se articula la sociedad romana ${ }^{26}$. El presuntamente neutral -en cuanto radicalmente abstracto- concepto de persona constituye, ciertamente, el pretexto para llevar a cabo/instaurar/establecer ciertas categorizaciones de la sociedad, y con ello pasa a ser un instrumento de dominio. Así, con tal propósito, expresa Gayo en otros lugares que un determinado principio era válido para los esclavos y "también para las otras personas, las que se someten a nuestro poder" ("eadem de ceteris quoque personis, quae nostro iuri subiectae") ${ }^{27}$. La distribución de los hombres en los diferentes estatus sociales, con derechos distintos y acentuados fuertemente, corresponde también a la antigua idea expresada en primer lugar por Platón y Aristóteles ${ }^{28}$.

Así afirmado por Gayo, la distinción más importante en relación al estatus es aquella entre libres y esclavos. Concentrémonos entonces en dicha distinción, y precisamente en aquella forma que duró aproximadamente hasta fines de la república.

\section{Libres y esclavos.}

El hombre libre puede hacer todo lo que no está prohibido, mientras que el esclavo puede hacer sólo lo que le es ordenado. El hombre libre es -bajo nuestra terminología- persona, sujeto entonces de derechos y obligaciones; el esclavo, en cambio, es una $\cos ^{29}$ y es tratado en forma análoga a las bestias ${ }^{30}$. Esta analogía debe tomarse en el sentido pleno del término: el propietario podía decidir qué actividad encargar al esclavo y tenía derecho a matarlo ${ }^{31}$. El hombre libre es sujeto de derechos ${ }^{32}$, y por

\footnotetext{
${ }^{25}$ Sobre esto también Agnati, Ugo, cit. (n. 21), pp. 15-25; Gaudemet, Jean, “Membrum, Persona, Status", en SDHI., 61 (1995), pp. 1 s.; Zululeta, Francisco de, The Institutes of Gaius (Oxford, 1953), II, p. 23. Por tanto incorrecto GIOFFrEDI, Carlo, Aspetti della sistematica Gaiana, en GIOFFredI, Carlo (editor), Nuovi studi di diritto greco e romano (Roma, 1980), p. 243.

${ }^{26}$ Sobre esto Agnati, Ugo, cit. (n. 21), pp. 12-17.

${ }^{27}$ Gai. 4,135.

${ }^{28}$ Cfr. en Albanese, Bernardo, Le persone nel diritto romano privato (Palermo, 1979), pp. 347-348.

${ }^{29}$ Gai. 2,13: "Servile caput nullum ius habet"; V. también D. 4,5,3,1; 48,10,7.

${ }^{30}$ Gai. 2,13.

${ }^{31}$ Buckland, William, Roman Law of Slavery (Oxford 1908).

${ }^{32}$ Ribas Alba, cit. (n. 20), p. 237.
} 
lo tanto agente; el esclavo es objeto de derecho: objeto, entonces de la acción ajena ${ }^{33}$. Este poder se atenuaba solo por la cura morum del censor ${ }^{34}$.

Un contraste más fuerte es inimaginable. Tomemos por un momento en serio la metáfora del papel que la persona juega en la escena de la vida: imaginemos que un director artístico cualquiera encuentre dos recién nacidos y ponga uno en la cuna de un hombre libre, que llamaremos con el típico nombre de Seio, y otro en la cuna, mucho más humilde, de un esclavo, que llamaremos con un nombre típico de los esclavos: Pánfilo. Pánfilo podría ser más bello, más generoso, más inteligente y más capaz que Seio, pero siempre tendrá un rol subordinado: tendrá que servir a Seio, en el peor de los casos como un animal de trabajo en uno de los latifundios de Seio, en el mejor de los casos en una de las casas de Seio, con la oportunidad de ascenso social que podría culminar en la liberación de Pánfilo por parte de Seio. En la literatura antigua, el ejemplo paradigmático de tal carrera -y también del precio que por ella tenía que pagarse- está representado por Trimalción, el personaje del Satyricon de Petronio.

La diferencia de estatus entre libres y esclavos podía llevar a formas extremas de crueldad. De hecho, constituía no solo una sencilla distinción entre estatus, sino también el fundamento del sistema económico, y, de hecho, en tal grado que Max Weber pudo comparar la necesidad de los esclavos para la economía del mundo antiguo con la necesidad de carbón para alto horno ${ }^{35}$. Los antiguos romanos, por tanto, se disgustaban cuando se ponían en duda las bases de este sistema económico y social. El senatus consultum Silanianum ${ }^{36} \mathrm{del}$ año $10 \mathrm{~d}$. C., a partir del cual todos los esclavos de una familia tenían que ser matados si el amo hubiera sido matado por alguno de ellos, lo demuestra de una manera impresionante. "Quot servi, tot hostes" (“¡Se tienen tantos enemigos cuantos son los esclavos!”), decía el famoso proverbio. Tácito inició un debate que tuvo lugar en el senado, en el que se trató de aplicar esta regla a una familia de ¡360! esclavos $^{37}$ : Tac., ann.14,40 ss. [44]: "Suspecta maioribus nostris fuerunt ingenia servorum, etiam cum in agris aut domibus $i[s]$ dem nascerentur caritatemque dominorum statim acciperent. postquam vero nationes in familiis habemus, quibus diversi ritus, externa sacra aut nulla sunt, conluviem istam non nisi metu coercueris. at quidam insontes peribunt. nam et ex fuso exercitu cum decimus quisque fustiferitur, etiam strenui sortiuntur. habet aliquid ex iniquo omne magnum

${ }^{33}$ Albanese, Bernardo, cit. (n. 28), p. 108.

${ }^{34}$ Giltaij, Jacob, cit. (n. 18), pp. 55-60.

${ }^{35}$ Weber, Max, Die sozialen Gründe des Unterganges der antiken Kultur, en Schriften 1894-1922 (Stuttgart, 2002), p. 57.

${ }^{36}$ Giltaij, Jacob, cit. (n. 18), pp. 61-65.

${ }^{37}$ Tac., ann. 14, 40 ss. [44] 
exemplum, quod contra singulos utilitate singulos utilitate publica rependitur" ("La naturaleza de los esclavos era intuida por nuestros antepasados, aunque ellos hubiesen nacido en la propiedad de estos últimos, y hubiesen crecido en el respeto a su amo. Ya tenemos diferentes nacionalidades en el interior de nuestras familias, que tienen rituales diferentes, exóticos o ningún ritual. Una masa tal no se puede controlar sino con el miedo. Pero [se podría objetar que contra la aplicación del s.c. Silanianum que] de esta manera mueren también los inocentes. Sin embargo, hasta en un ejército vencido, en el que se mata a un hombre cada diez a bastonazos, también los valientes están sorteados. Cada gran ejemplo que se pueda dar contra el singular para la utilidad general trae lamentablemente consigo algo de injusto").

Los esclavos fueron ejecutados por decisión del emperador en contra de la opinión del pueblo de Roma.

De modo entonces que, originariamente, persona tenía un significado preciso. El concepto servía para la discriminación jurídica en la forma más aguda que se pueda imaginar.

\section{Nacidos libres y libertos.}

La única posibilidad de escapar del papel de esclavo para el resto de la vida era la liberación ${ }^{38}$. Pero, tampoco ésta llevaba a una igualdad jurídica con el libertador. Por el contrario, según Gayo, la diferencia más importante de la categoría de los hombres libres es aquella que existe entre los nacidos libres (ingenui) y los puestos en libertad (liberti o bien libertini) $)^{39}$. El liberto estaba sujeto a la patria potestas de su libertador, o sea, de su manumisor ${ }^{40}$, para quien debía realizar labores cotidianas (operae) y al que estaba obligado a constituirlo como heredero ${ }^{41}$. La relación de clientela que resultaba a partir de la liberación muestra grandes paralelismos con la relación -de la que nos ocuparemos más adelante- entre el pater familias y sus hijos in potestate. Los libertos no podían ocupar ningún cargo religioso o estatal elevado ${ }^{42}$. El matrimonio con persona de rango senatorial le estaba prohibido por la legislación matrimonial de la época augustea ${ }^{43}$. En un primer momento, los niños de los libertos tenían el estatus del nacido libre. Socialmente el estatus del liberto no era ventajoso, sino que se veía

${ }^{38}$ Albanese, Bernardo, cit. (n. 28), pp. 22-45.

${ }^{39}$ Sobre esto Albanese, Bernardo, cit. (n. 28), pp. 57-63; Mantello, Antonio, cit. (n. ¡Error! Marcador no definido.), pp. 203-210.

${ }^{40}$ Albanese, Bernardo, cit. (n. 28), pp. 63-68.

${ }^{41}$ Sobre el ius patronatus GUZMÁN BRITO, Alejandro, cit. (n. 10), pp. 352-353.

${ }^{42}$ Albanese, Bernardo, cit. (n. 28), p. 58.

${ }^{43}$ Ibíd., pp. 59 s. 
como un defecto ${ }^{44}$. Para los libertos de grandes amos, sobre todo aquellos del emperador y de sus parientes, la liberación podía significar el momento inicial de una escalada social, habiendo recibido bienes e instaurado relaciones y conocidos.

\section{Romanos y extranjeros.}

La posición jurídica de los extranjeros, y por lo tanto el status civitatis, corresponde a la segunda diferencia más importante sobre el estatus al interior de la categoría de los libres ${ }^{45}$. Los enemigos de guerra estaban privados completamente de derechos. Eran matados o esclavizados. Otros extranjeros eran reconocidos como libres, pero no tenían lugar alguno en la sociedad romana, toda vez que era una sociedad de culto ${ }^{46}$. Esta (estridente) exclusión de la sociedad civil fue superada a través de la atribución del commercium, es decir, del derecho de concluir contratos que producen efectos $^{47}$, y del connubium, es decir, del derecho de contraer matrimonio válido bajo el derecho romano con un ciudadano de Roma ${ }^{48}$. Naturalmente, el extranjero no tenía ningún derecho político. En su forma originaria, se podría decir, que no era ni sujeto de derechos ni objeto de derechos: sencillamente el ordenamiento jurídico no lo tomaba en consideración ${ }^{49}$. Sin embargo, más tarde fueron reconocidos derechos también al extranjero, a tal punto que Chiusi pudo afirmar al respecto que en ello se manifestaba un "reconocimiento de los derechos del individuo en cuanto tal"

\section{El "paterfamilias" y sus dependientes.}

Las relaciones entre los individuos libres en una posición superior y aquellos en una posición inferior al interior de la familia ${ }^{51}$ reproducen, en

${ }^{44}$ Ibíd., p. 58.

${ }^{45}$ Ibíd., pp. 192-197; MANTELLO, Antonio, cit. (n. ¡Error! Marcador no definido.), pp. 193-99; CHIUsI, Tiziana, Lo straniero come comparticipe dell esperienza giuridicaA proposito dello stato giuridico dello straniero a Roma, en MAFFI, Alberto - Gagliardi, Lorenzo (editores), I diritti degli altri in Grecia e a Roma (St. Augustin, 2011), pp. $27-41$.

${ }^{46}$ Albanese, Bernardo, cit. (n. 28), pp. 192-195.

${ }^{47}$ Kaser, Max, Das römische Privatrecht (2a edición, München, 1971), I, pp. 35-36.

${ }^{48}$ Ibíd., p. 75.

${ }^{49}$ Así también SPENGLER, Hans-Dietrich, Zum Menschenbild der römischen Juristen, en Juristenzeitung (2011), p. 1025.

${ }^{50}$ Chiusi, Tiziana, cit. (n. 45), p. 44.

${ }^{51}$ Una visión general sobre la familia y las relaciones jurídicas a su interior en: Corbino, Alessandro, "Status familiae", en Corbino, Alessandro y otros (editores), "Homo, caput, persona". La costruzione giuridica dell identità nell esperienza romana (Pavia, 2010), pp. 175-216; TAFArO, Sebastiano, cit. (n. 14), pp. 41-45. 
pequeña escala, la relación entre amo y esclavo ${ }^{52}$ : la diferencia más importante al interior de la familia es aquella entre personae sui iuris y personae alieni iuris ${ }^{3}$. El jefe de la familia es el pater familias. Mientras éste esté vivo, sus descendientes se someten a la patria potestas, la autoridad paterna, o sea, son alieni iuris. Él puede castigar a sus propios hijos ${ }^{54}$, venderlos como esclavos $\mathrm{y}^{55}$, en algunos casos extremos, matarlos ${ }^{56}$. En particular, los hijos no pueden ser titulares de bienes: "quien está sometido al poder paterno no puede tener ningún bien para sî" ("qui in potestate est nibil suum habere potest $\left.{ }^{257}\right)$. Estas prerrogativas estaban solo controladas por medio de la religión y de los usos ${ }^{58}$. Con la muerte del pater familias cesa la subordinación de los hijos y cada descendiente se convierte sui iuris, de la misma manera en que había sido el padre. En cambio, en el derecho público los filii familias estaban al mismo nivel que sus padres, podían entonces ocupar cargos públicos ${ }^{59}$.

La forma originaria del matrimonio (cum manu) conducía a la adquisición, por parte de la mujer, de la posición jurídica de una hija, o sea era filiae loco. Este poder del marido, llamado manus, era grosso modo tan amplio como la potestas sobre el hijo ${ }^{60}$. En particular, la mujer no podía ser titular de bienes ${ }^{61}$. Según una regla instituida por Rómulo, era probablemente lícito que el padre rechazara el alimento a todas las hijas, excepto a la mayor ${ }^{62}$. Si la mujer es descubierta en adulterio flagrante, quien tiene el poder sobre ella tiene el derecho de matarla ${ }^{63}$. En general vale lo señalado por Papiniano, que "en muchas de nuestras disposiciones jurídicas la posición de la mujer es peor que la del hombre" " in multis iuris nostri articolis deterior est condicio feminarum quam masculorum") ${ }^{64}$.

Si el pater familias está incapacitado y sus descendientes son menores de edad o incapaces de actuar, en su lugar es nombrado un curador, nor-

${ }^{52}$ Albanese, Bernardo, cit. (n. 28), p. 271; GuZmán Brito, Alejandro, cit. (n. $10)$, p. 324.

${ }^{53}$ Mantello, Antonio, cit. (n. ¡Error! Marcador no definido.), pp. 209-235.

${ }^{54}$ Albanese, Bernardo, cit. (n. 28), p. 250.

${ }^{55}$ Amunátegui Perelló, Carlos Felipe, Origen de los poderes del "paterfamilias". El "paterfamilias" y la "patria potestas" (Madrid, 2009), pp. 133 ss.

${ }^{56}$ Ibíd., pp. 48 ss.

${ }^{57}$ Gai. 2, 87.

${ }^{58}$ Amunátegui Perelló, Carlos Felipe, cit. (n. 55), pp. 95 ss., 124 ss.

${ }^{59}$ Albanese, Bernardo, cit. (n. 28), pp. $246 \mathrm{~s}$.

${ }^{60}$ Sulla discussione in tema Amunátegui Perelló, Carlos Felipe, cit. (n. 55), pp. 255 ss.

${ }^{61}$ Albanese, Bernardo, cit. (n. 28), pp. 289-293.

${ }^{62}$ Ibíd., pp. 351-352.

${ }^{63}$ Ibíd., p. 352.

${ }^{64}$ D. 1.5.9. Sobre esto: Ibíd., pp. 347-350. V. también Gai 2,113, donde se ilustra una excepción que confirma la regla. 
malmente el pariente del grado más próximo. Si una mujer no está ni bajo la patria potestas del padre ni bajo la manus de su marido ${ }^{65}$, entonces se le nombra un tutor, sin cuyo consentimiento no podrá realizar negocios jurídicos eficaces.

\section{El "pater familias" como corona de la creación.}

Hasta aquí hemos entregado una visión general del ius personarum en cuanto derecho de los estatus sociales en Roma hasta aproximadamente el nacimiento de Cristo. En la cima de la pirámide social está el pater familias, que domina a todos en su casa, dotado hasta del poder más extremo incluso el de matar. Todos los individuos que no están en esta condición, se hallan en una relación de subordinación más o menos fuerte, regulada en el derecho de las personas. Entre los romanos se tenía una persona, es decir un papel o un estatus, pero no se era persona en el sentido que nosotros lo entendemos en la actualidad ${ }^{66}$. Solo el pater familias era una persona en el significado que le damos hoy ${ }^{67}$. Mientras el concepto de persona servía a los romanos para fijar numerosas diferencias de estatus entre los individuos, para nosotros este concepto sirve para considerar iguales a todos los seres humanos: cada uno es naturalmente persona y posee, en cuanto tal, los mismos derechos y deberes. Nosotros no conocemos ni esclavos ni libertos, los extranjeros gozan de todos los derechos fundamentales y humanos, incluso algunos derechos políticos ${ }^{68}$. Las instituciones del poder paterno, de la manus sobre la esposa, así como de la tutela sobre la mujer nos son desconocidas. Entonces, la función del concepto de persona ha cambiado de manera determinante: ya no sirve para establecer una discriminación jurídica, sino más bien para representar al hombre que se ha liberado de sus cadenas del estatus, que, con la ayuda del Estado de derecho liberal, puede ser "faber fortunae suae" ". Detrás del cambio de este concepto reside un cambio en el derecho, y naturalmente también en la concepción social.

${ }^{65}$ Manus y patria potestas son recíprocamente excluyentes: Amunátegui Perelló, Carlos Felipe, cit. (n. 55), pp. 332 ss.

${ }^{66}$ Mantovani, Dario, Lessico dell identità, en Corbino, Alessandro y otros (editores), "Homo, caput, persona". La costruzione giuridica dell identità nell esperienza romana (Pavia, 2010), p. 39.

${ }^{67}$ Casavola, Franco, I diritti umani (Milano, 1997), p. 3; Gaudemet, Jean, Des 'droits de Phomme' ont-ils été reconnus dans IEmpire Romain? en Labeo, 33 (1987), p. 9.

${ }^{68}$ Artículo 28 inciso $1^{\circ}$ Constitución alemana (derecho electoral activo comunal para extra-comunitarios)

${ }^{69}$ Una detallada discusión iusnaturalista sobre el concepto de persona y sus aplicaciones para la libertad del hombre en Messner, Johannes, Das Naturrecht (7 ${ }^{\mathrm{a}}$ edición, Berlin, 1984), $\$ 13$. 
Aquel proceso de transformación fue inaugurado por el mismo derecho romano, que antes había introducido la categoría de iure personarum para establecer la discriminación. Pero, ¿cómo se llega a esta inversión de los valores (“Umwertung aller Werte”)?

\section{LA DisOlUCión de LAS CADENAS DE los "STATUS"} POR OBRA DE LOS JURISTAS ROMANOS

El sistema romano clásico de los estatus recién descrito se empieza a disgregar progresivamente a partir del siglo I d. C., cuando empezó a afirmarse la idea de que los esclavos no eran sólo cosas, sino también personae en el sentido moderno de la palabra ${ }^{70}$. Aquello se manifiesta en muchas ocasiones. En vista de que los esclavos desde el punto de vista jurídico no eran sujetos de derecho, no podían contraer matrimonio. Su unión no tenía ningún significado jurídico y era llamada sencillamente contubernium, es decir, "dormitorio". Sin embargo, los juristas se esforzaron por encontrar soluciones con objeto de que tales contubernia no se pudieran disolver por sus amos salvo en situaciónes excepcionales ${ }^{71}$. Además, se reconocían los grados de parentesco de los esclavos (cognatio servilis) y a partir de estos se deducían, por ejemplo, las prohibiciones de incesto del mismo modo a como sucedía entre los hombres libres ${ }^{72}$. Además, como entre los libres, las esclavas llevaban la dote a sus maridos. Ahora, en el caso en que al terminar el matrimonio la esclava pidiera la restitución de la dote, ¿le correspondía alguna acción de acuerdo con el derecho romano? Los juristas establecieron que aquello era posible, aunque la lógica del sistema habría requerido adoptar una solución diferente, tal como: "desde el momento en que los esclavos no pueden contraer matrimonio, ni les es permitido llevar una dote en el sentido jurídico, la esclava no está legitimada para el ejercicio de una acción para repetir la dote"73. En particular los juristas, recurriendo a la legislación imperial, formularon un principio jurídico (favor libertatis ${ }^{7 /}$ ) según el cual, frente a la duda, se tendría que decidir a favor de la libertad del esclavo ${ }^{75}$.

${ }^{70}$ Spengler, Hans-Dietrich, cit. (n. 49), p. 1027. Ejemplos para esta tendencia: GuZMÁn Brito, Alejandro, cit. (n. 10), pp. 346-347.

${ }^{71}$ Albanese, Bernardo, cit. (n. 28), p. 109.

${ }^{72}$ Ibíd., p. 109.

${ }^{73}$ Ulp. D. 23,3,39; Proc. D. 23,3,67.

${ }^{74}$ Albanese, Bernardo, cit. (n. 28), p. 20 nota 7.

${ }^{75}$ Sobre esto: Giltaij, Jacob, cit. (n. 18), pp. 49-50; Stagl, Jakob Fortunat, Glanz der Rhetorik und Finsternis der Logik in einer Enscheidung Marc Aurels (Marcell. D. 28, 4, 3 pr.-1), en Fundamina, 20 (2014), pp.862-871. Muy escéptico Urbanik, 
El poder ejercitado por el liberador sobre el liberto estaba fuertemente limitado; en particular el amo podía perder sus derechos de patronus en el caso en que fuera culpable de las más graves violaciones de su dignidad frente al ex esclavo. También los trabajos cotidianos obligatorios fueron cada vez más frecuentemente objeto de regulación bajo tutela del liberto ${ }^{76}$.

Los extranjeros rápidamente se igualaron a los ciudadanos romanos. El derecho vigente en las relaciones entre éstos y los romanos era el derecho común derivado del derecho natural (ius gentium). De hecho, este último no era más que el derecho romano depurado de su especificidad ${ }^{77}$. La administración de la justicia entre extranjeros, y entre éstos y los romanos, estaba gestionada por un oficio especial, aquel del pretor peregrino. Con la constitutio Antoniniana del año $212 d$. C., el ordenamiento jurídico romano se extendió prácticamente a todos los habitantes del imperio ${ }^{78}$. El estatus del extranjero perdió así su nitidez.

Ciertamente, la institución de la patria potestas fue conservada en el plano formal pero sufrió una drástica atenuación en sus consecuencias. Ya en la época del nacimiento de Cristo el poder de sancionar y de matar no se ejercía. Además, los descendientes adquirieron el derecho de alimentos ${ }^{79}$, que representaba una limitación de la patria potestas ${ }^{80}$. La incapacidad nominal de poseer bienes fue evitada de la siguiente manera: se entregaba a los hijos un patrimonio especial, el peculium, con el que podían concluir negocios de forma autónoma ${ }^{81}$. Esto tenía como consecuencia que los hijos hombres podían contraer obligaciones a nombre propio ${ }^{82}$. En algunas ocasiones el peculium fue entregado también a los esclavos, de tal modo que podían conducir los negocios del amo autónomamente ${ }^{83}$. Aquello hizo posible el

Jakub, On the Uselessness of it All: The Roman Law of Marriage and Modern Times, en Fundamina 20 (2014), p. 947.

${ }^{76}$ Sobre esto: MASI Doria, Carla, "Bona libertorum" (Napoli, 1996), passim; WaldSteIn, Wolfgang, "Operae libertorum” (Wien, 1986), passim; y WaldSTEIN, Ins Herz geschrieben (Augsburg, 2010), pp. 551-576.

${ }^{77}$ Destaca fundamentalmente el significado de este cambio: Spengler, HansDietrich, cit. (n. 49), p. 1025. Sobre el ius gentium STURm, Fritz, "Ius Gentium". Imperialistische Schönfärberei römischer Juristen, en MusCHELER, Karl-Heinz (editor), Römische Jurisprudenz. Dogmatik Überlieferung Rezeption (Berlin, 2011), pp. 663670.

${ }^{78}$ WiEACKER, Franz, Römische Rechtsgeschichte (München, 2006), II, pp. 159-162.

${ }^{79}$ Albanese, Bernardo, cit. (n. 28), pp. 260-268.

${ }^{80}$ Ibíd., p. 269.

${ }^{81}$ KASER, Max, RPR. cit. (n. 47), p. 343.

${ }^{82}$ Albanese, Bernardo, cit. (n. 28), pp. 275-278.

${ }^{83}$ KASER, Max, RPR cit. (n. 47), pp. 605-609; BÜRgE, Alfons, Lo schiavo (in) dipendente e il suo patrimonio, en Corbino, Alessandro y otros, (editores), "Homo, caput, persona". La costruzione giuridica dell identità nell esperienza romana (Pavia, 
ascenso social de muchos esclavos, aunque no debe olvidarse que se trató de una posibilidad concedida solo a un pequeño grupo ${ }^{84}$.

Un patrimonio especial de tal envergadura estaba presente en el estamento alto, en particular para las mujeres, en forma de paràpherna: generalmente, la parte de la herencia de la hija se ofrecía como dote al control del marido. Gradualmente, las dotes empezaron a reducirse y el patrimonio puesto a disposición de la mujer (paràpherna), a acrecentarse $\mathrm{e}^{85}$. De tal manera, la forma del matrimonio con manus del hombre sobre la mujer se debilitó y fue sustituida por el matrimonio manus ${ }^{86}$. Así la mujer se transformaba en capaz de actuar y podía separarse del marido en cada momento con las siguientes palabras: "tuas res tibi habito" (" $\mathrm{i}$ Toma tus cosas!”) o “tuas res tibi agito” (“AArréglatelas!”) ${ }^{87}$.

La tutela de las mujeres se mantuvo formalmente, pero al mismo tiempo fue altamente discutida. Como muestra el siguiente texto, Gai. 1.190: "Feminas vero perfectae aetatis in tutela esse fere nulla pretiosa ratio suasisse videtur: Nam quae vulgo creditur, quin levitate animi plerumque decipiuntur et aequum erat eas tutorum auctoritate regi, magis speciosa videtur quam vera; mulieres enim, quae perfectae aetatis sunt, ipsae sibi negotia tractant, et in quibusdam causis dicis gratia tutor interponit auctoritatem suam; saepe etiam invitus auctor fieri a praetore cogitur" ("Pero, para que las mujeres de plena edad estén en tutela, ninguna razón puede convencer suficientemente; pues lo que vulgarmente se cree, de que es justo que sean gobernadas por la autoridad de los tutores, debido a que están frecuentemente expuestas a engaño por su ligereza, resulta una razón de más apariencia que verdad; pues las mujeres de plena edad realizan los negocios por sí mismas, y en algunos casos el tutor interpone su autoridad por pura fórmula; y frecuentemente incluso contra su voluntad, obligado por el pretor").

En la práctica se las arreglaban nombrando a un esclavo libre como tutor: en virtud de los poderes de su liberadora, era él quien tenía que hacer todo lo que ella quisiera y no viceversa ${ }^{88}$.

Así asistimos a una de las disoluciones de las rígidas diferencias en-

2010), pp. 369-385; BuchwiTz, Wolfram, Fremde Sklaven als Erben. Sozialer Aufstieg durch Dritte, en Corbino, Alessandro y otros (editores), "Homo, caput, persona". La costruzione giuridica dell identità nell esperienza romana (Pavia, 2010), pp. 393425.

${ }^{84}$ FInLey, Moses, Die Sklaverei in der Antike (München, 1981), passim.

${ }^{85}$ STAGL, Jakob Fortunat, "Favor dotis". Die Privilegierung im System des Römischen Rechts (Wien, 2009), pp. 222-256.

${ }^{86}$ Kaser, Max - KNÜtel, Rolf, Römisches Privatrecht (20ª edición, München, 2014), $\$ 58 / 9$.

${ }^{87}$ Gai. D. $24,2,2,1$

${ }^{88}$ Cic., p. Mur. 12, 27. 
tre estatus comprendidas en el concepto de ius personarum. Esta fue el resultado de la obra de los juristas y de la legislación imperial ${ }^{89}$. Si aquellos no hubieran aprobado tal tendencia, se habría quedado en el régimen antiguo. Es posible ver la intencionalidad de la transformación en el esfuerzo, que fue más profuso, puesto en modificar conscientemente tal situación.

\section{IV. “Unum LaCtum BIBERUNT": MUTACIÓN DEL CONCEPTO DE PERSONA}

A la mutación de la sociedad romana la acompañó una mutación del concepto de persona. En el lenguaje jurídico de la edad clásica, y especialmente postclásica, el concepto ya no se refiere al hombre entre sus cadenas del estatus, por el contrario se refiere al hombre desprovisto de tales cadenas, en el bien y en el mal ${ }^{90}$. Esto se manifiesta, por ejemplo, en un pasaje de las Iustiniani Instituciones del VI siglo d. C. ${ }^{91}$ (Inst. 4, 1, 5): "Poena manifesti furti quadrupli est tam ex servi persona quam ex liberi, nec manifesti dupli" ("La pena del hurto flagrante es del cuádruplo, tanto respecto a la persona de un esclavo como a la de un hombre libre; y del duplo la del no flagrante").-

Persona servi, es decir la "persona del esclavo", indica que el esclavo, en cuanto es esclavo, puede ser perseguido. En cambio, según la ya superada concepción republicana, el esclavo no era tomado en consideración por el derecho, y por esta razón no era siquiera punible en el sentido técnico en el caso que hubiera realizado una acción ilícita, por lo tanto su amo tenía el derecho de castigarlo o de entregarlo a la parte agraviada ${ }^{92}$. Por el hecho que éste ahora fuese punible-como cualquier otro-se extrae un reconocimiento al esclavo como ser humano, como persona en el sentido moderno ${ }^{93}$. Y esta nueva cualidad del esclavo fue proporcionada por el término persona. Así como los delitos cometidos por el esclavo son sancionados de la misma manera que aquellos cometidos por un hombre libre, también los delitos

${ }^{89}$ KASER, Max, RPR, cit. (n. 47), pp. 285-286.

${ }^{90}$ Berger, Adolf, s. v. "Persona", en Encyclopaedic Dictionary of Roman Law (Philadelphia, 1953), pp. 628-629. V. también Esposito, Robert, Terza Persona. Politica della vita e filosofia dell impersonale (Torino, 2007), p. 101.

${ }^{91}$ V. también: Gai. 1,120 s.; Gai. 3,189; D. 15,1,52 pr.; D. 23,3,46 pr.; D. $31,82,2$; D. 35,2,21,1; D. 39,6,23; D. 45,3,1,4; D. 47,10,15,44; D. 50,16,215; D. 50,17,22 pr.; Inst. 4,4,7; 4,7 pr.; FV. 82; CTh. 4,10,1; CI. 9,47,11; 7,16,35; 4,36,1 pr.; $2,11,10$.

${ }^{92}$ Gaudemet, Jean, cit. (n. 67), p. 14; Robinson, Olivia, The Criminal Law of Ancient Rome (Baltimore, 1995), p. 15; y para su desarrollo GiLTAIJ, Jacob, cit. (n. 18), pp. 104-110.

${ }^{93}$ Del mismo modo Giltaij, Jacob, cit. (n. 18), pp. 139-184, y para un toque final Esposito, Robert, Terza Persona, cit. (90), p. 87 con ref. a Hannah Arendt. 
cometidos contra los esclavos son sancionados como si estos fueran libres, siempre que su amo quisiera, como señala Gayo ${ }^{94}$. Quadrato justamente recalca que también en esto se manifiesta el reconocimiento del esclavo como persona en el sentido moderno ${ }^{95}$.

Entonces, el concepto de persona se emplea ya no como genus, en el cual la persona servilis sería una species, sino más bien como concepto para designar al hombre liberado de sus cadenas de estatus con relación al hecho de que tiene derechos y deberes o, en otras palabras, persona designa aquí al sujeto de derecho.

La información entregada por el texto de que esta persona es adicionalmente un esclavo- expresada ya través de un genitivo (servi) o a través de un adjetivo (servilis) - es, por un lado, necesaria, desde el momento en que esta categoría jurídica es aún válida, pero, por el otro lado, incómoda, en cuanto es un obstáculo para el sentido que se pretende dar, es decir, aquel de "individuo" con independencia de su condición (sujeto de derecho). El concepto de persona ya había adquirido este sentido fuera del lenguaje técnico jurídico ${ }^{96}$. Mas no era posible trasladar dicho uso al léxico jurídico, porque el sistema de los estatus aún era el derecho vigente, disolviéndose sólo poco a poco. Este desarrollo aparece esbozado en Gai. 1, 9, donde todos los individuos son recogidos por el mismo concepto de persona ${ }^{97}$. El producto de este desarrollo es el reconocimiento del esclavo como persona en nuestro sentido moderno ${ }^{98}$.

De modo más general, el mismo desarrollo se manifiesta en un nivel teórico más elaborado en una serie de textos jurídicos tardo clásicos (fines del siglo III D.C.). En D. 1,5,2, el jurista Hermogeniano dice ante todo, reuniendo las bases elaboradas por sus predecesores: "Cum igitur hominum causa omne ius constitutum sit, primo de personarum statu [...] dicemus" ("Ya que todo el derecho ha sido constituido en razón de los hombres, tratemos en primer lugar de las personas").

Por lo tanto, se presenta la necesidad de hacerse cargo de la cuestión relacionada a la función que cumple el concepto de persona en el lenguaje jurídico. Schloßmann señaló, en una investigación realizada a inicios del

${ }^{94}$ Gai. 3,213.

${ }^{95}$ Quadrato, Renato, cit. (n. ¡Error! Marcador no definido.), pp. 10-25.

${ }^{96}$ GeOrges, Karl Ernst, s. v. "Persona", en Ausführliches lateinisch-deutsches Handwörterbuch (Hannover, 1913), II, coll. 1641-1642. Un ejemplo en Séneca epist. 94, 1.

${ }^{97}$ Así Agnati, Ugo, cit. (n. 21), pp. 33-37.

${ }_{98}$ Del mismo modo este resultado en Albanese, Bernardo, cit. (n. 28), pp. 108109; Quadrato, Renato, cit. (n. ¡Error! Marcador no definido.), pp. 10-18; y TAFARO, Sebastiano, cit. (n. 14), pp. 14-22, 65. 
siglo $\mathrm{XX}$, que esta no cumplía ninguna, en cuanto que el concepto de persona es idéntico al de ser humano ${ }^{99}$. Sin embargo, podemos afirmar que la verdadera función del concepto de persona consiste en garantizar tal identidad, como muestra inequívocamente el artículo 16 del código civil austriaco. El concepto de persona atribuye al hombre una cierta dignidad natural, un "Menschenadel" (nobleza natural del hombre) en el sentido de Schiller -sin que esta exija otras garantías especiales- y excluye con esto un sistema de estatus sociales rígidos, que era aquel de la república romana ${ }^{100}$. Pero el concepto de persona no habría podido cumplir esta función si los juristas romanos no le hubieran dado otra interpretación a la palabra persona. De ese modo, Rodotà formula esta idea con estricta claridad, aunque no se esté refiriendo al derecho romano, sino al constitucionalismo moderno: “A través de la construcción del sujeto abstracto fue posible liberar formalmente a la persona de la casta de la servidumbre, del trabajo, de la condición económica, del sexo, que fundaban la sociedad jerárquica, de la desigualdad [...] aquel nacer 'libres e iguales' que inaugura la Constitución norteamericana, ${ }^{101}$ no es el registro de un dato de la naturaleza, sino la transposición en el orden jurídico de otra idea de individuo ${ }^{102}$." Así nos encontramos con la pregunta sobre qué estuvo detrás de esta interpretación diferente, de esa "otra idea del individuo".

Esta "otra idea" necesitaba de un concepto que abarcara a todos los hombres. ¿Cómo fue que los juristas romanos eligieron el término persona? ¿Por qué no tomaron el término homo, por ejemplo? Como todos sabemos, esta última palabra significa "hombre" y habría reflejado adecuadamente la idea de que el esclavo también es sujeto de derechos, a la par del pater familias $^{103}$. Hay una frase del liberto Trimalción que muestra esta idea de modo clarísimo: "Los esclavos son hombres y han bebido la misma leche aunque la mala suerte los oprima"104 ("et servi homines sunt et aeque unum

${ }^{99}$ Ribas Alba, cit. (n. 20), pp. 236 s.; Vistos estos hechos Schlossmann, Sieg-

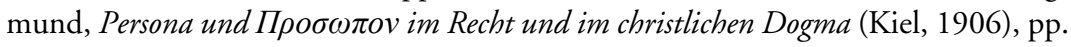
1-6, polemiza de modo feroz contra el valor de este concepto en la jurisprudencia.

${ }^{100}$ Hacia esta dirección también: FADDA, Carlo, Diritto della persona e della famiglia (Napoli, 1911), p. 6; y Quadrato, Renato, cit. (n. ¡Error! Marcador no definido.), p. 4. Melillo, Generoso, "Persona", "status" e "condijo" nell esperienza romana. La dogmatica moderna, en SDHI., 73 (2007), p. 95; además pero diverso Agnati, Ugo, cit. (n. 21), pp. 19-23, aunque se refiere más a Gayo.

${ }^{101}$ No es así. "We hold these thruth's to be self-evident, that all men are created equal [...]" está al inicio de la Declaration of Independence de 1776.

${ }^{102}$ Rodotà, Stefano, Dal soggetto alla persona (Napoli, 2007), p. 13.

${ }^{103}$ Por ejemplo en Gai. 1,1 y 1,162. V. también Ribas Alba, cit. (n. 20), pp. $15-24,32 \mathrm{~s}$.

${ }^{104}$ Sat. $71,1$. 
lactum biberunt etiam si illos malus fatus oppresserit') ${ }^{105}$. La explicación es sencilla. Con frecuencia sucede que un término general adquiera un sentido negativo (por ejemplo 'das Mensch' en el dialecto vienés significa una "mujer torpe"). En la época de Gayo, y todavía después, el término homo designaba, en el lenguaje jurídico, sobre todo al "esclavo", como vislumbra Fuhrmann, y por lo tanto no era adecuado para cumplir la función de término general aplicable a todos los hombres (en el sentido moderno $)^{106}$. La manifestación más clara de este uso jurídico la encontramos en la fórmula de la vindicación: "Este esclavo (homo!) me pertenece por el derecho de los quirites" 107 . Entonces, es evidente el gran mérito del término persona que, como Mantovani recientemente ha observado, es una hoja en blanco que puede llenarse con cualquier contenido, incluido también aquel del homo en el sentido biológico ${ }^{108}$, en el sentido de "ser humano"109.

\section{EL AGENTE DE LA MUTACIÓN: EL DERECHO NATURAL ROMANO}

El derecho civil romano no tenía el potencial teórico para superar las diferencias entre los estatus sociales construidos en el ius personarum; en cambio, un potencial así se encontraba en una categoría especial del derecho, que los griegos elaboraron y los romanos perfeccionaron: el derecho natural ${ }^{110}$. En las Instituciones se puede encontrar su definición, Inst. 1,2 pr.: "Ius naturale est quod natura omnia animalia docuit... hinc descendit maris atque feminae coniugatio, quam nos matrimonium appellamus, hinc liberorum procreatio et educatio [...]" ("El derecho natural es el orden dado a todos los seres vivos... de aquí deriva la unión entre hombre y mujer, 372.

${ }^{105}$ V. también Quadrato, Renato, cit. (n. ¡Error! Marcador no definido.), p.

${ }^{106}$ Heumann, Hermann Gottlieb - Seckel, Emil, s.v. “Homo” 3, en Handlexikon $z u$ den Quellen des römischen Rechts (9a edición, Jena, 1926), p. 226. Así también QuAdrato, Renato, cit. (n. ¡Error! Marcador no definido.), pp. 4 s.

${ }^{107}$ Gai. 4,16.

${ }^{108}$ Mantovani, Dario, cit. (n. 66), p. 38; Thomas, Yan, Le sujet de droit, la personne et la nature, en Le Débat, 100 (1998), p. 98.

${ }^{109}$ Notas de QuAdrato, Renato, cit. (n. ¡Error! Marcador no definido.), p. 348; esta es, precisamente, la actitud de los juristas, por lo menos la de Gayo.

${ }^{110}$ WaLdSTEIN, Wolfgang, Entscheidungsgrundlagen römischer Juristen, en TEMPORINI, Hildegard (editora), Aufstieg und Niedergang der römischen Welt (Berlin, 1976), XV, pp. 3, 89-95; WaLdstein, Wolfgang, Herz cit. (n. 76), pp. 31-43; Neschke-HentschKe, Ada, Platonisme politique et théorie du droit naturel (Louvainla-Neuve, 1995, 2003), I-II. passim. 
que llamamos matrimonio, así como la procreación y la educación de los hijos [...]).

El derecho natural se ve a sí mismo como un cuerpo de disposiciones jurídicas inmutables, que rigen de modo independiente del ordenamiento estatal y regulan fundamentalmente los aspectos esenciales de una adecuada convivencia humana. Tales disposiciones son dadas naturalmente y no están sujetas a mutación, no son hechas por el hombre, como por ej. la Creación. Los romanos aplicaban el derecho natural en parte para fundar las disposiciones jurídicas en sectores internos del derecho, pero también como una reserva del pensamiento humanitario a la que recurrir en el caso que exista una laguna o una aporía en el derecho tradicional ${ }^{111}$.

Un presupuesto indispensable para el derecho natural es un concepto unitario de hombre, concepto sobre cuya formación estamos informados: el fragmento de Gayo citado inicialmente utiliza, como ya se ha dicho, el concepto de persona para todos los seres humanos. Esta operación de abstracción no se manifiesta casualmente, sino que fue elaborada por la escuela estoica $^{112}$. Panecio de Rodas enseñaba ${ }^{113}$, según lo señalado por Cicerón, que cada hombre tiene cuatro personae (o componentes): la racionalidad, que es común para todos, la individualidad, que se determina a través de alma y cuerpo, el destino y la propia voluntad. Cic., De off. 1,107 y 115 (30) ${ }^{114}$ : (107) "Intellegendum etiam est duabus quasi nos a natura indutos esse personis; quarum una communis est ex eo, quod omnes participes sumus rationis praestantiaeque eius, qua antecellimus bestiis, a qua omne honestum decorumque trahitur et ex qua ratio inveniendi officii exquiritur, altera autem quae proprie singulis est tributa. ut enim in corporibus magnae dissimilitudines sunt, alios videmus velocitate ad cursum, alios viribus ad luctandum valere, itemque in formis aliis dignitatem inesse, aliis venustatem, sic in animis existunt maiores etiam varietates. (115) Ac duabus iis personis, quas supra dixi, tertia adiungitur, quam casus aliqui aut tempus imponit, quarta etiam, quam nobismet ipsis iudicio nostro accommodamus. nam regna, imperia, nobilitatem, honores, divitiae, opes eaque, quae sunt his contraria, in casu sita temporibus gubernantur; ipsi autem gerere quam personam velimus, a nostra voluntate proficiscitur. Itaque se alii ad philosophiam, alii ad ius civile, alii ad eloquentiam applicant, ipsarumque virtutum in alia alius mavult excellere"

${ }^{111}$ STAGL, Jakob Fortunat, "Favor dotis", cit (n. 85), pp. 98-99.

${ }^{112}$ Sobre la antropología arcaia: RibAs AlbA, cit. (n. 20), pp. 37-58.

${ }^{113}$ Sobre este texto, ibíd., pp. 193-216.

${ }^{114}$ V. Forschner, Maximlian, Der Begriff der Person in der Stoa, en STURMa, Dieter (editor), Person. Philosophiegeschichte, Theoretische Philosophie, Praktische Philosophie (Paderborn, 2001), pp. 40-45; STeinmetz, Peter, Die Stoa, en Flashar, Hellmut (editor), Grundriss der Geschichte der Philosophie (Basel, 1994), IV,2, pp. 656-657. 
[(107) "También hemos de reflexionar sobre que nos ha revestido, por decirlo así, de dos personas la naturaleza: una común, que es por la que todos participamos de la razón y de aquella nobleza con que excedemos a las bestias, de la cual resulta el conocimiento para hallar las obligaciones y guardar el decoro, y la otra particular, que es como el distintivo de cada individuo. Porque al modo en que observamos en los cuerpos tanta diversidad que unos son a propósito por su ligereza para correr, otros por sus fuerzas para luchar, y asimismo en los rostros: en unos gracia y en otros una seriedad majestuosa, así también en los ánimos existen aún mayores variedades (115) A las dos personas del hombre que se han demostrado ya, se añade otra tercera que imponen las circunstancias o la casualidad, y otro cuarta que nos tomamos nosotros por propia elección. Porque los reinos, noblezas, imperios, riquezas y las cosas contrarias a estas que dependen de la casualidad, se gobiernan por las circunstancias de los tiempos, mas el personaje que hemos de representar en el mundo depende totalmente de nuestro libre albedrío, y así unos se aplican a la filosofía, otros al derecho civil, otros a la elocuencia, y aun, en las mismas virtudes, unos procuran aventajarse más en una y otros en otro"].

Esta enseñanza, claramente inspirada en las cuatro causas de Aristóteles (causa formalis, materialis, efficiens y finalis), constituye el presupuesto teórico para poder llegar a las afirmaciones de carácter general sobre el hombre - en caso contrario, este intento debería fracasar a causa de la disparidad de las condiciones de vida. La teoría de Panecio aclaró el hecho de que, sin perjuicio de las diferencias enormes entre los seres humanos existen ciertos aspectos comunes - de modo particular la racionalidad. De otra manera, la subsistencia de tales diferencias habría impedido reconducir a todos los hombres al interior de una categoría unitaria. Scarano Ussani ha sostenido plausiblemente ${ }^{15}$ que la teoría de Panecio habría inspirado el uso originario del concepto de persona en el sentido de sujeto de derechos (naturalmente no con referencia al esclavo) ${ }^{116}$.

No obstante, el pensamiento iusnaturalista no se ha detenido a elaborar afirmaciones generales sobre el hombre, si bien el reconocimiento de la cualidad de ser humano al esclavo constituye un significativo avance. A partir del derecho natural, los romanos extrajeron el postulado de la libertad y de la igualdad de todos los hombres, como se ve en D. 1,5,4,1 (Florent., 59 instit.): "Servitus est constitutio iuris gentium, qua quis dominio alieno contra naturam subicitur" ("La esclavitud es una institución del derecho común, en razón del cual un hombre está sujeto en contra de la naturaleza

\footnotetext{
${ }^{115}$ UsSani, Vincenzo, cit. (n. 22), pp. 243 ss.

${ }^{116}$ Cic., De leg. 2,19,28.
} 
al dominio de otro"); y D. 50,17,32 (Ulp., 43 Sab.): "Quod attinet ad ius civile, servi pro nullius habentur: non tamen et iure naturali, quia, quod ad ius naturalem attinet, omnes homines aequales sunt" ("Por lo que atañe al derecho civil, los esclavos son considerados como si no fueran nada; mas no por el derecho natural, porque por lo que atañe al derecho natural todos los hombres son iguales").

De acuerdo al derecho de la ciudad de Roma los esclavos son considerados como nada, pero esto no vale para el derecho natural, porque por cuanto a lo que ello se refiere, todos los hombres son iguales. Entonces, ¿cómo se podía justificar la existencia de la esclavitud, si se habían escrito tales cosas? Detengámonos en una postura expresada con tal propósito al inicio de las Instituciones justinianeas (Inst. 1,2,2): "Ius autem gentium omni humano generi commune est. Nam usu exigente et humanis necessitatibus gentes humanae quaedam sibi constituerunt: bella etenim orta sunt et captivitates secutae et servitutes, quae sunt iuri naturali contrariae (iure enim naturali ab initio omnes homines liberi nascebantur) [...]". Como lo demuestra la citación de las Instituciones los romanos oponían al derecho natural consideraciones de tipo utilitaristas, las cuales sin embargo no están en condición de justificar algo, o constituyen una débil justificación. Y era una ilusión pensar que ambos sistemas de legitimación de las decisiones sociales -el derecho de la ciudad de Roma y el derecho natural- pudieran subsistir uno al lado del otro sin alguna conexión entre ellos y, puestos uno al frente del otro, se sacaran el sombrero como dos vecinos que se encuentran casualmente por la calle. Era oportuno prever que el derecho natural, en breve o largo tiempo, habría obtenido la primacía, ganando la batalla ideológica ${ }^{117}$. Detrás de la disolución de los roles sociales, de los estatus, y detrás del colateral cambio de valores del concepto de persona se encuentra el derecho natural romano: según su pensamiento fundamental, las diferencias jurídicas, así como las había previsto el antiguo derecho, no son más susceptibles de legitimidad. Por lo tanto, el derecho natural deslegitimó el sistema romano de los estatus y creó las condiciones decisivas para su disgregación ${ }^{118}$.

A decir verdad, los romanos no lograron construir una doctrina de derechos fundamentales partiendo del derecho natural y sus preceptos, porque -según la explicación verosímil de Schiavone- no habían aún descubierto

${ }^{117}$ Hay una historia propia acerca de la relación de los Padres de la Iglesia con la esclavitud: esta es vista como una justa pena para el pecado: Augustinus, De civ. Dei 19,5. V. KLEIN, Richard, Die Sklaverei in der Sicht der Bischöfe Ambrosius und Augustinus (Stuttgart, 1988), pp. 87-105.

${ }^{118}$ Con numerosas pruebas de apoyo: Agnati, Ugo, cit. (n. 21), pp. 21-25; TAFARO, Sebastiano, cit. (n. 14), pp. 142-183. 
el individualismo necesario para ello ${ }^{119}$. Esto habría sucedido sólo después, cuando a los derechos fundamentales se les "aplicó los dientes" (célebre formulación del constitucionalista alemán Günter Dürig), declarando estos derechos subjetivos accionables en un juicio ${ }^{120}$ - cosa que sucedió sólo después de la Segunda Guerra Mundial, en Alemania con la Constitución de 1949 (artículo 19, inciso 4º y en Italia con la Constitución de 1948 (artículo 2). Concluyente para esta individualización fue el cristianismo, sobre todo en su forma protestante ${ }^{121}$, que se fundó nuevamente sobre el concepto de persona así formulado por los juristas romanos.

\section{VI. "Magnum Miraculum eST HOMO"}

Hemos intentado mostrar cómo el concepto de persona ha servido primero para privar al hombre de sus derechos, y luego para dotarlo de ellos. Responsables de este vuelco de valores y del contextual cambio conceptual fueron los juristas inspirados por el derecho natural ${ }^{122}$, de tal modo que el mérito de estos juristas romanos ha llegado hasta nosotros, y los textos escritos por ellos han tenido un efecto incalculable en la historia de Occidente ${ }^{123}$. Las Instituciones de Justiniano, repetidas veces citadas, pertenecen, junto con la Biblia, a los libros más impresos y leídos del Occidente ${ }^{124}$. Por casi 1500 años cada estudiante de derecho ha comenzado sus estudios con sus lecturas. El desarrollo de la concepción del esclavo de bestia a individuo, era el presupuesto para que el concepto de persona, en el sentido de individuo racional, pudiera acceder primero a la filosofía y luego a la teología ${ }^{125}$. La definición de persona entregada por Boecio (ca. 480-525) "persona est naturae rationabilis individua substantia" 126 ("sustancia individual con naturaleza racional"), fundamental

${ }^{119}$ Schiavone, Aldo, “Ius". L'invenzione del diritto in Occidente (Torino, 2005), pp. 390-401.

${ }^{120} \mathrm{El}$ nexo entre individualismo y derechos fundamentales subjetivos es destacado también por GAUDEMET, Jean, cit. (n. 67), p. 8.

${ }^{121}$ CoIng, Helmut, cit. (n. 5), pp. 193-198. Para el individualismo de corte protestante v. STARK, Wener, The Sociology of Religion (London, 1972), V, pp. 274-281.

${ }^{122}$ Así también Spengler, Hans-Dietrich, cit. (n. 49), pp. 1028-1030.

${ }^{123}$ WIEACKER, Franz, cit. (cit. 78), p. 88.

${ }^{124}$ Behrends, Okko - Knu tel, Rolf - Kupisch, Bernhard - Seiler, Hans Hermann, Corpus Iuris Civilis (Text und U bersetzung), I: Institutionen (Heidelberg, 1990), p. 289.

${ }^{125}$ Mantovani, Dario, cit. (n. 66), p. 40, retiene que esta mutación de valores sucedió como fruto temprano del cristianismo. Sobre el destino del concepto jurídico de persona en la Teología: RibAS AlbA, cit. (n. 20), pp. 283-312.

${ }^{126}$ BoETH., c. Eut. 3,4. 
para Occidente, habría sido impensable sin un cambio conceptual. La nueva determinación del concepto se refiere al hombre en cuanto tal y no explora su estatus. Ella es el producto de la actividad subversiva, llamada justamente por Spengler "revolucionaria" ${ }^{27}$, realizada por los juristas de la edad imperial e inspirada por el derecho natural. Los juristas romanos, dotados de un cierto gusto anárquico, clavaron el hacha en el árbol sobre el que estaban junto con los demás ciudadanos. Y estos juristas no eran cualesquiera personas, pues ocupaban los oficios más altos de la res publi$c a^{128}$. Sin embargo, no se trataba de cínicos alegres o un "e grege Epicuri porcum" $" 29$. Por el contrario, ellos estaban inspirados por una profunda confianza en el valor de su gestión. Si luego el primer cristianismo estuvo involucrado, es otra cuestión ${ }^{130}$. Recientemente Quadrato, por ejemplo, ha intentado probar la vieja hipótesis de que Justiniano habría llamado a Gayo noster porque era un cristiano ${ }^{131}$. De hecho, se nota inmediatamente que Gayo critica de continuo el derecho vigente, motivo por el cual Nörr, en su monografía sobre la crítica del derecho de los romanos, dedica un capítulo entero a Gayo como "Rechtskritiker" "32. El programa detrás de la crítica de Gayo podría ser extraído del Nuevo Testamento (Gal. 3, 27 s.): "[...] pues todos los que habéis sido bautizados en Cristo, de Cristo estáis revestidos. Ya no hay judio ni griego; no hay esclavo ni libre; no hay hombre ni mujer, porque todos vosotros sois uno en Cristo Jesús”. Es Gayo el primero en tratar a todos los hombres bajo el término de persona, y de esa manera reconoce su cualidad de hombre - no solo en el plano social sino también en el jurídico ${ }^{133}$ - una operación que ha suscitado la sospecha de la romanística moderna sobre que él era anormal o bien un mal jurista ${ }^{134}$. Y es siempre Gayo quien dice que a los esclavos no hay que darle bastonazos sin razón ${ }^{135}$; es él el autor de la regla "Libertas omnibus rebus favorabilior est.” (D. 50,17,122). Finalmente, también es Gayo quien explica cuán ridícula es la tutela mulierum $(1,190)$.

${ }^{127}$ SPENGLER, Hans-Dietrich, cit. (n. 49), pp. 1029-1031.

${ }^{128}$ Sobre esto: SCHIAVONE, Aldo, cit. (n. 119), pp. 390-401.

${ }^{129}$ Hor., ep. 1,4,16.

${ }^{130}$ Sobre esto BiOnDI, Biondo, Il diritto romano cristiano (Milano, 1952), I, pp. 98-123.

${ }^{131}$ Quadrato, Renato, cit. (n. ¡Error! Marcador no definido.), pp. 357-363.

${ }^{132}$ NÖRR, Dieter, Rechtskritik in der römischen Antike (München, 1974), pp. 92102.

${ }^{133}$ GAUdEMET, Jean, cit. (n. 67), p. 14 n. 32.

${ }^{134}$ Schlossmann, Siegmund, cit. (n. 99), p. 32; y Quadrato, Renato, cit. (n. ¡Error! Marcador no definido.), p. 4.

${ }^{135}$ Gai. 1, 53; GamauF, Richard, "Ad statuam licet confugere" (Frankfurt a. M., 1999), pp. 81-88. 
Es verdad que el concepto de persona destapó su efectivo "potencial antropológico" (Spaemann) a partir del Medioevo cristiano y luego en las épocas sucesivas ${ }^{136}$. En tal sentido, Tomás de Aquino, ampliando la definición de Boecio, estableció la unicidad del hombre singular ${ }^{137}$ y así cada uno adquirió dignidad respecto del prójimo y hacia $\operatorname{Dios}^{138}$. En el curso del tiempo el concepto de persona cristiano-tomista se separó de sus orígenes cristianos para devenir en un concepto jurídico-laico. En cuanto al núcleo del concepto moderno de persona, por ejemplo de la manera en que está tomado como base de la Declaración Universal de los Derechos del Hombre de las Naciones Unidas de 1948, o de la Carta de los derechos fundamentales de la Unión Europea ${ }^{139}$, se puede coincidir con Spaemann en que la persona en cuanto tal tiene dignidad, es decir, que cada quien está obligado "respecto del portador de tal dignidad, llamado persona, a justificar cada acción cuyas consecuencias le conciernen" ${ }^{140}$. La misma cosa dijo, en palabras más bellas, Rosmini, el amigo de Manzoni: "La persona del hombre es el derecho subsistente: entonces también la esencia del derecho ${ }^{141 "}$.

${ }^{136}$ Sobre esto Spaemann, Robert, Was macht Personen zu Personen?, en Thomas, Hans - Hattler, Johannes (editores), Personen. Zum Miteinander einmaliger Freiheitswesen (Frankfurt a. M., 2012), pp. 29-46; SPAEMANN, Robert, me parece que el título principal de este libro también es: Personen Versuche über den Unterschied von zwischen "etwas" und "jemand" ( $3^{a}$ edicíon, Stuttgart, 2006), passim; v. también Moreschini, Claudio, Oltre PAntico. La svolta antropologica di Agostino e la definizione boeziana di persona, en Corbino, Alessandro y otros (editores), "Homo, caput, persona”. La costruzione giuridica dell identità nell esperienza romana (Pavia, 2010), pp. $91-112$.

${ }^{137}$ Summa Theologiae III, q. xvi, a. 12, ad 2. Sobre esto MeumertZheim, Bernhard, Menschliche Person und Willensfreiheit bei Thomas von Aquin (Köln Univ., Diss., 1961), pp. 6-23; y UGARTE GODOY, José Joaquín, Curso de filosofía del derecho (Santiago, 2010), I, pp. 236-240; Ugarte Godoy, José Joaquín, El derecho de la vida (Santiago, 2006), pp. 68-78. Sobre el término de persona en la edad Media: v. Kreuzer, Johann, Der Begriff der Person in der Philosophie des Mittelalters, en STurMA, Dieter (editor) Person. Philosophiegeschichte, Theoretische Philosophie, Praktische Philosophie (Paderborn, 2001), pp. 59-77.

${ }^{138}$ Heinzmann, Richard, Der Menschen als Person. Zum Verständnis des Gewissens bei Thomas von Aquin, in Gründel, Johannes (editor), Das Gewissen: subjektive Willkür oder oberste Willkür (Düsseldorf, 1990), pp. 34-52.

${ }^{139}$ Artículo 3: "Derecho a la integridad de la persona, inciso $1^{\circ}$ : "Cada individuo tiene derecho a la integridad fisica y psíquica".

${ }^{140}$ Spaemann, Robert, Versuche, cit. (n. 136), p. 30. En el mismo sentido desde la perspectiva del derecho vigente PerLINGIERI, Pietro, La persona e i suoi diritti, cit. (n. 12), p. 26.

${ }^{141}$ Rosmini-Serbati, Antonio, Filosofia del diritto (Milano, 1841, 1845), I, p. 224. 


\section{BiBLIOGRAFíA}

Agnati, Ugo, "Persona iuris vocabulum”. Per un’interpretazione giuridica di persona nelle opere di Gaio, en Rivista di Diritto Romano, 9 (2009).

Albanese, Bernardo, Le persone nel diritto romano privato (Palermo, 1979).

Amunátegui Perelló, Carlos Felipe, Origen de los poderes del "paterfamilias". El "paterfamilias" y la "patria potestas" (Madrid, 2009).

Behrends, Okko - Knütel, Rolf - Kupisch, Bernhard - Seiler, Hans Hermann, Corpus Iuris Civilis (Text und U bersetzung), I Institutionen (Heidelberg 1990).

Berger, Adolf, s. v. "Persona”, en Encyclopaedic Dictionary of Roman Law (Philadelphia, 1953).

BIONDI, Biondo, Il diritto romano cristiano (Milano, 1952), I.

Blumenthal, Albrecht von, s. v. "Person", en Kroll, Wilhelm (editor), Realencyclopädie der classischen Altertumswissenschaft, Neue Bearbeitung (Stuttgart, 1937), XXXVII.

Boniolo, Giovanni - De Anna, Gabriele - Vincenti, Ugo, Individuo e persona. Tre saggi su chi siamo (Milano, 2007).

Buchwitz, Wolfram, Fremde Sklaven als Erben. Sozialer Aufstieg durch Dritte, en Corbino, Alessandro y otros, (editores), "Homo, caput, persona". La costruzione giuridica dell'identità nell'esperienza romana (Pavia, 2010).

BÜrGe, Alfons, Lo schiavo (in)dipendente e il suo patrimonio, en CorBINo, Alessandro y otros (editores), "Homo, caput, persona". La costruzione giuridica dell'identità nell'esperienza romana (Pavia, 2010).

Casavola, Franco, I diritti umani (Milano, 1997).

Chiusi, Tiziana, Lo straniero come comparticipe dell'esperienza giuridica.A proposito dello stato giuridico dello straniero a Roma, en MAFFI, Alberto - Gagliardi, Lorenzo (editores), I diritti degli altri in Grecia e a Roma (St. Augustin, 2011).

CoIng, Helmut, Der Rechtsbegriff der menschlichen Person und die Theorien der Menschenrechte, en WolfF, Ernst (editor), Beiträge zur Rechtsforschung. Sonderveröffentlichung der Zeitschrift für Ausländisches und Internationales Privatrecht (Tübingen, 1950).

Corbino, Alessandro, Familiae, en Corbino, Alessandro y otros (editores), "Homo, caput, persona”. La costruzione giuridica dell'identità nell'esperienza romana (Pavia, 2010).

Enneccerus, Ludwig - Nipperdey, Hans Carl, Allgemeiner Teil des Bürgerlichen Rechts (15 edición, Tübingen, 1959).

Finley, Moses, Die Sklaverei in der Antike (München, 1981).

Esposito, Robert, Terza Persona. Politica della vita e filosofia dell'impersonale (Torino, 2007).

FADDA, Carlo, Diritto della persona e della famiglia (Napoli, 1911).

Forschner, Maximlian, Der Begriff der Person in der Stoa, en STURMa, Dieter (editor), Person. Philosophiegeschichte, Theoretische Philosophie, Praktische Philosophie (Paderborn, 2001).

Fuhrmann, Manfred, s. v. "Persona”, en RitTer, Joachim (editor), Historisches Wörterbuch der Philosophie (Darmstadt, 1989),VII.

Gamauf, Richard, "Ad statuam licet confugere”(Frankfurt a. M., 1999).

Gaudemet, Jean, "Membrum, Persona, Status", en SDHI., 61, 1995. 
Gaudemet, Jean, Des “droits de l'homme” ont-ils été reconnus dans l'Empire Romain?, en Labeo, 33 (1987).

Georges, Karl Ernst, s. v. "Persona", en Ausführliches lateinisch-deutsches Handwörterbuch (Hannover, 1913), II.

Giltaij, Jacob, Mensenrechten in het Romeinse recht? (Nijmegen, 2011).

Gioffredi, Carlo, Aspetti della sistematica Gaiana, en Gioffredi, Carlo (editor), Nuovi studi di diritto greco e romano (Roma, 1980).

Gómez DÁvila, Nicolas, Escolios a un texto implícito (Madrid, 2009).

Grimm, Jakob - Grimm, Wilhelm, s. v. "Person”, en Deutsches Wörterbuch (Stuttgart, 1889), XIII.

Grotius, Hugo, De iure belli ac pacis (Madrid, Centro de Estudios Constitucionales). GuZmán Brito, Alejandro, Derecho privado romano (2a edición, Santiago, 2013), I. Hattenhauer, Hans, Grundbegriffe des bürgerlichen Rechts (2a edicíon, München, 2000).

Heinzmann, Richard, Der Menschen als Person. Zum Verständnis des Gewissens bei Thomas von Aquin, en GRÜNDEL, Johannes (editor), Das Gewissen: subjektive Willkür oder oberste Willkür (Düsseldorf, 1990).

Heumann, Hermann Gottlieb - Seckel, Emil, s. v. "Homo" (3), en Handlexikon zu den Quellen des römischen Rechts (9a edición, Jena, 1926).

Новљвашм, Eric, Il secolo breve. 1914-1991 (Milano, 1995).

ISENSEE, Josef, Staatsrechtliche Grundlagen des Sozialstaatsprinzips, en Katholische Akademie Schwerte (editor), Die Würde des Menschen in unbezahlbar. Der Sozialstaat zwischen Anspruch und Wirklichkeit (Paderborn, 2011).

IsENSEE, Josef, Juristische Person, en Isensee, Josef - Kirchhof, Paul (editores), Handbuch des Staatsrecht der Bundesrepublik Deutschland (Heidelberg, 2011, IX.

KaSER, Max - KNÜTel, Rolf, Römisches Privatrecht (20ª edición, München, 2014).

KaSer, Max, Das römische Privatrecht, (2a edición, München, 1971), I.

Kelsen, Hans, Allgemeine Staatslehre (Berlin, 1925).

KLEIn, Richard, Die Sklaverei in der Sicht der Bischöfe Amrosius und Augustinus (Stuttgart, 1988).

Kreuzer, Johann, Der Begriff der Person in der Philosophie des Mittelalters, en STURma, Dieter (editor), Person. Philosophiegeschichte, Theoretische Philosophie, Praktische Philosophie (Paderborn, 2001).

Lyon Puelma, Alberto, Personas naturales (Santiago, 2007).

Mantello, Antonio, Lezioni di diritto romano (Torino, 2004), II.

Mantovani, Dario, Lessico dell'identità, en Corbino, Alessandro y otros (editores), "Homo, caput, persona". La costruzione giuridica dell'identità nell'esperienza romana (Pavia, 2010).

Maritain, Jacques, Les droits de l'homme et la loi naturelle (Paris, 1947).

Messner, Johannes, Das Naturrecht (7a edición, Berlin, 1984).

MAsi Doria, Carla, "Bona libertorum" (Napoli, 1996).

Melillo, Generoso: "Persona", "status" e "condijo" nell'esperienza romana. La dogmatica moderna, en SDHI., 73 (2007).

Meumertzheim, Bernhard, Menschliche Person und Willensfreiheit bei Thomas von Aquin (Köln Univ., Diss., 1961).

Heinzmann, Richard, Der Menschen als Person. Zum Verständnis des Gewissens bei Thomas von Aquin, en GRÜNDEL, Johannes (editor), Das Gewissen: subjektive Willkür oder oberste Willkür (Düsseldorf, 1990). 
MarX, Karl - Engels, Friedrich, Werke (Berlin 1947), XIII.

Mommsen, Theodor, Römisches Strafrecht (Leipzig, 1899).

Moreschini, Claudio, Oltre l'antico. La svolta antropologica di Agostino e la definizione boeziana di persona, en Corbino, Alessandro y otros (editores), "Homo, caput, persona”. La costruzione giuridica dell'identità nell'esperienza romana (Pavia, 2010).

NeschKe-HentschKe, Ada, Platonisme politique et théorie du droit naturel (Louvainla-Neuve, 1995, 2003), I-II.

NöRR, Dieter, Rechtskritik in der römischen Antike (München, 1974).

Perlingieri, Pietro, La persona e i suoi diritti (Napoli, 2005).

Perlingieri, Pietro, La personalità umana nel ordinamento giuridico (Napoli, 1972).

Pugliese, Giovanni, Appunti per una storia della protezione dei diritti umani, en VACCA, Letizia (editora) Scritti giuridici (1985-1995) (Napoli, 2007).

QuADRATO, Renato, "Gaius dixit”. La voce di un giurista di frontiera (Bari, 2010).

REINHARD, Wolfgang, Geschichte der europäischen Expansion (Stuttgart, 1983-1990).

Ribas Alba, José María, Persona desde el derecho romano a la teología cristiana (2a edición, Granada, Comares 2012).

Robinson, Olivia, The Criminal Law of Ancient Rome (Baltimore, 1995).

Rodotà, Stefano, Antropologia del "homo dignus", en Civilistica. Com. Revista Eletrónica di Direito Civil, 2 (2013).

Rodotà, Stefano, Dal soggetto alla persona (Napoli, 2007).

Rosmini-Serbati, Antonio, Filosofia del diritto (Milano, 1841, 1845), I-II.

SCARANo Ussani, Vincenzo, La scoperta della persona, en Ostraka, 18 (2009).

Schiavone, Aldo, "Ius". L'invenzione del diritto in Occidente (Torino, 2005).

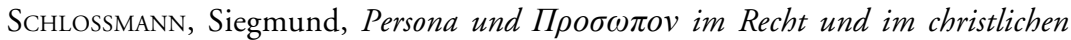
Dogma (Kiel, 1906).

Sснмітт, Jochem: $\$ 1$ sez. 6 , en Münchener Kommentar zum BGB (6a edición, München, 2012).

Snowdon, Paul, "Peter Frederick Strawson", en The Stanford Encyclopedia of Philosophy, 2009, URL = http://plato.stanford.edu/archives/fall2009/entries/strawson/ (10 de octubre de 2012)

Spaemann, Robert, Was macht Personen zu Personen? en Thomas, Hans - HattLER, Johannes (editores), Personen. Zum Miteinander einmaliger Freiheitswesen (Frankfurt a. M., 2012).

Spaemann, Robert, Versuche über den Unterschied von zwischen "etwas" und "jemand" (3a edición, Stuttgart, 2006).

SPENGLER, Hans-Dietrich, Zum Menschenbild der römischen Juristen, en Juristenzeitung (2011).

SPIVAK, Gayatri, Can the subaltern speak? Speculations on Widow-Sacrifice, en Wedge $7-8,(1985)$.

Stagl, Jakob Fortunat, Da "qualcosa" a "qualcuno", da "qualcuno" a "qualcosa". Percorsi esatti ed errati sull concetto di persona, en BuONGIORNO, Pierangelo - LOHSSE, Sebastian (editores), "Fontes iuris". Atti del VI Jahrestreffen Junger Romanistinnen und Romanisten. Lecce, 30-31 marzo 2012 (Napoli 2013).

STAGL, Jakob Fortunat, Glanz der Rhetorik und Finsternis der Logik in einer Enscheidung Marc Aurels (Marcell. D. 28, 4, 3 pr.-1), en Fundamina, 20 (2014).

STAGL, Jakob Fortunat, The Rule of Law of Law against the Rule of Greed. Edmund Burke against the East India Company, en Rechtsgeschichte 20 (2012). 
STAGL, Jakob Fortunat, "Favor dotis". Die Privilegierung im System des Römischen Rechts (Wien, 2009).

STARK, Wener, The Sociology of Religion (London, 1972), V..

Steinmetz, Peter, Die Stoa, en Flashar, Hellmut (editor), Grundriss der Geschichte der Philosophie (Basel, 1994), IV,2

STURM, Fritz, "Ius gentium”. Imperialistische Schönfärberei römischer Juristen, en Muscheler, Karl-Heinz (editor), Römische Jurisprudenz. Dogmatik Überlieferung Rezeption (Berlin, 2011).

TAFArO, Sebastiano, "Ius hominum causa constitutum" (Napoli, 2009).

Thomas, Yan, Le sujet de droit, la personne et la nature, en Le Débat, 100 (1998).

Ugarte Godor, José Joaquín, Curso de filosofía del derecho (Santiago, 2010), I.

Ugarte Godoy, José Joaquín, El derecho de la vida (Santiago, 2006).

URBANIK, Jakub, On the Uselessness of it All: The Roman Law of Marriage and Modern Times, en Fundamina 20 (2014).

VeYne, Paul, Le pain et le cirque (Paris, 1976).

Waldstein, Wolfgang, "Patroni" e "liberti", en Corbino, Alessandro, Familiae, en Corbino, Alessandro y otros (editores), "Homo, caput, persona". La costruzione giuridica dell'identità nell'esperienza romana (Pavia, 2010).

WaldSTEIN, Wolfgang, "Operae libertorum”(Wien, 1986).

WALDSTEIN, Wolfgang, Entscheidungsgrundlagen römischer Juristen, en TEMPORINI, Hildegard (editora), Aufstieg und Niedergang der römischen Welt (Berlin, 1976), XV. WaldsteIn, Ins Herz geschrieben (Augsburg, 2010).

Weber, Max, Die sozialen Gründe des Unterganges der antiken Kultur, en Schriften 1894-1922 (Stuttgart, 2002).

WeIL, Simone, La personne et le sacré, en Écrits de Londre et dernières lettres (Paris, 1957).

WIEACKER, Franz, Römische Rechtsgeschichte (München, 2006), II.

WindsCHEID, Bernhard - KIPP, Theodor, Lehrbuch des Pandektenrechts (9a edición, Frankfurt am Main, 1908).

Zululeta, Francisco de, The Institutes of Gaius (Oxford, 1953), II. 
